\title{
PLACING DYNAMIC SENSORS AND ACTUATORS ON FLEXIBLE SPACE STRUCTURES
}

\author{
Gregory A. Norris and Robert E. Skelton \\ Purdue University
}

\begin{abstract}
Input/Output Cost Analysis involves decompositions of the quadratic cost function into contributions from each stochastic input and each weighted output. In the past, these suboptimal cost decomposition methods of sensor and actuator selection (SAS) have been used to locate perfect (infinite bandwidth) sensors and actuators on large scale systems. This paper extends these ideas to the more practical case of imperfect actuators and sensors with dynamics of their own. NASA's SCOLE examples demonstrate that sensor and actuator dynamics affect the optimal selection and placement of sensors and actluators.
\end{abstract}




\subsection{INTRODUCTION}

The objective of this paper is to develop and evaluate a method for the selection of sensors and actuators in the control of finite-dimensional linear systems using imperfect sensors and actuators -- devices which do not provide instantaneous responses, but have nontrivial dynamics of their own. In addition, the plant noise and the measurement noise is assumed correlated. This important case allows the use of accelerometers as sensors (this always yields correlated plant and measurement noise). Application of the generalized method to practical control problems demonstrates that correlatedness of the noise and the dynamics of the actuator and sensor devices can significantly affect the optimal selection of both the number and location of sensors and actuators.

Consider as a starting point the following familiar dynamic system model:

$$
\begin{gathered}
\dot{\mathrm{x}}_{\mathrm{p}}=\mathrm{A}_{\mathrm{p}} \mathrm{x}_{\mathrm{p}}(\mathrm{t})+\mathrm{B}_{\mathrm{p}}[\mathrm{f}(\mathrm{t})+\mathrm{w}(\mathrm{t})] \\
\mathrm{y}_{\mathrm{p}}(\mathrm{t})=\mathrm{C}_{\mathrm{p}} \mathrm{x}_{\mathrm{p}}(\mathrm{t}), \mathrm{z}(\mathrm{t})=\mathrm{M}_{\mathrm{p}} \mathrm{x}_{\mathrm{p}}(\mathrm{t})+\mathrm{v}(\mathrm{t}) \\
E\left\{\mathrm{w}(\mathrm{t}) \mathrm{w}^{\mathrm{T}}(\tau)\right\}=\delta(\mathrm{t}-\tau) \mathrm{W}, E\left\{\mathrm{v}(\mathrm{t}) \mathrm{v}^{\mathrm{T}}(\tau)\right\}=\delta(\mathrm{t}-\tau) \mathrm{V}, E\left\{\mathrm{w}(\mathrm{t}) \mathrm{v}^{\mathrm{T}}(\tau)\right\}=\delta(\mathrm{t}-\tau) \mathrm{U}(1.1 \mathrm{c})
\end{gathered}
$$

where $x_{p} \in R^{n_{x}}, f \in R^{n_{v}}, w \in R^{n_{*}}, \quad z, v, \in R^{n_{z}}$ and $\left(A_{p}, C_{p}\right)$ observable, $\left(A_{p}, B_{p}\right)$ controllable and $\left(A_{p}, M_{p}\right)$ detectable. The vectors $w(t)$ and $v(t)$ are respectively zero mean white noise characterizations of the actuator and sensor noise.

In control of large space structures, the locations of sensors and actuators becomes a critically significant "degree of freedom" in control design [14, 20]. Among over 60 more recent contributions to the SAS problem, only [4], [7], [10], [11], and [12] consider noisy actuators (W, $\mathrm{V}$ nonzero). In all cases, the disturbances are modelled as Gaussian, white, and uncorrelated ( $\mathrm{W}, \mathrm{V}$ diagonal, $\mathrm{U}=0$ ). Most of the SAS literature takes no account of actuator or sensor dynamics. Two exceptions are McClamrock [19], and Howell and Baxter, [6]. In [1] the authors extend the cost decomposition approach [2] to

\section{8}


accommodate noise correlation between sensor and actuator noise sources (W, V not diagonal, $U \neq 0$ ). A key conclusion in [1] is that the proper sensor/actuator selection and placement can be drastically affected by noise correlation. For example, the deletion of a noise source (by making an actuator or sensor noise free) may degrade performance contrary to the usual expectations when noise sources are uncorrelated.

Very fast actuator dynamics may be neglected in stability considerations, [9]. A more thorough discussion of the effect of actuator dynamics is given by Goh and Caughey [8]. The analysis of [8] and [9] demonstrates that plant frequencies occurring above the actuator bandwidth can lead to closed loop instability, even for co-located sensors and actuators. Goh and Caughey do not address the problem of selection of dynamic actuators. That is the goal of this paper.

This paper is organized as follows. First the system model is augmented to include sensor and actuator dynamics. The closed-loop input and output costs are then developed for the fully augmented system, and they are used to define expressions which reflect the effectiveness of each dynamic actuator or sensor in minimizing the cost function. Finally, the method is illustrated by application both to small scale numerical examples and to NASA's SCOLE flexible space structure model. It is found that in the selection of noisy actuators and sensors, finite Jynamics can significantly affect selection results.

\subsection{MODELING DYNAMIC ACTUATORS AND SENSORS}

In [2] the results of Closed-Loop Input/Output Cost Analysis (CIOCA) were developed and applied to the Sensor and Actuator Selection problem (SAS) for systems of the form (1.1) under closed-loop control. In [1] the control $f(t)$ is the vector of optimal state estimate feedback controls:

\section{9}




$$
\begin{gathered}
f(t)=G x_{c}(t), G=-R^{-1} B_{p}^{T} K . \\
\dot{x}_{c}=A_{p} x_{c}(t)+B_{p} f(t)+F\left[z(t)-M_{p} x_{c}(t)\right], F=\left[P M_{p}^{T}+B_{p} U\right] V^{-1}, \\
0=K A_{p}+A_{p}^{T} K-K B_{p} R^{-1} B_{p}^{T} K+C_{p}^{T} Q C_{p} \\
0=\left[A_{p}-B_{p} U V^{-1} M_{p}\right] P+P\left[A_{p}-B_{p} U V^{-1} M_{p}\right]^{T}-P M_{p}^{T} V^{-1} M_{p} P \\
+B_{p} W B_{p}^{T}-B_{p} U V^{-1} U^{T} B_{p}^{T}
\end{gathered}
$$

which minimizes the cost function

$$
V=E_{\infty}\left\{\left\|y_{\mathrm{p}}(\mathrm{t})\right\|^{2} \mathrm{Q}+\|\mathrm{u}(\mathrm{t})\|^{2} \mathrm{R}\right\}, \mathrm{E}_{\infty} \triangleq \triangleq_{\mathrm{tim} \rightarrow \infty} \mathrm{E}[\cdot]
$$

where $x_{c} \in R^{n_{x}}$ is the vector of state estimates. The conclusion from [1] for this problem (1.1), (2.1) (2.2) is that when $U \neq 0$, the sensor/actuator selection results can be drasticaliy different.

\subsection{Adding Actuator Dynamics}

First the system (1.1) is augmented to include stable, observable, controllable actuator dynamics of arbitrary order.

$$
\begin{gathered}
\dot{x}_{a}=A_{a} x_{a}+B_{a}\left(u+w_{u}\right), \quad\left(A_{a}, B_{a}\right) \text { controllable } \\
f=C_{a} x_{a}, \quad\left(A_{a}, C_{a}\right) \text { observable, } x_{a} \in R^{n_{u}}, \quad f \in R^{n_{a}}
\end{gathered}
$$

Figure 2.1 presents schematic representations for actuator models of varying degrees of complexity; Figure $2.1 \mathrm{a}$ represents the non-dynamic actuator, while Figure $2.1 \mathrm{~b}$ represents the general model for a dynamic actuator with white noise. Note that for the non-dynamic actuator the noise $w(t)$ is purely additive with the input $u(t)$. In the case of dynamic actuators the analyst may consider the actuator's output (into the system) to

\section{0}




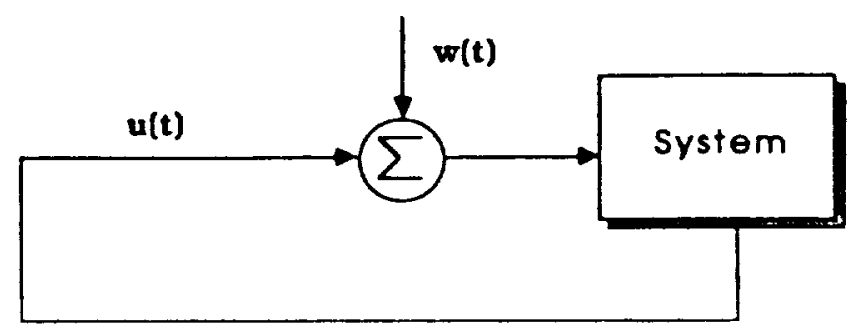

Figure 2.1a

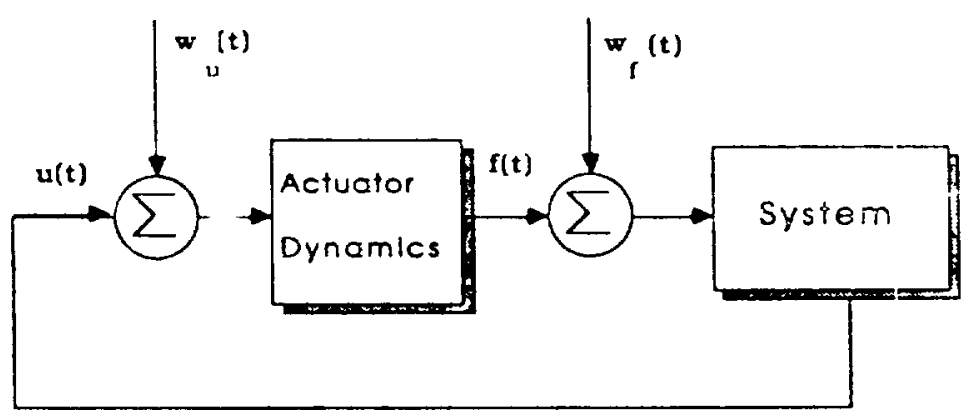

Figure 2.1b

Figure 2.1: Actuator Models 
include additive actuator output noise $w_{f}(t)$, or actuator command noise $w_{u}(t)$ which is filtered by the dynamics of the actuator, or both. Both types of noise are assumed possible in our development.

Augmenting the system states $x_{p}$ of the original system (2.1) with a vector of actuator states $x_{\mathrm{a}}$, we obtain:

$$
\begin{gathered}
\dot{x}=A x+B u+D w, y=C x, z=M x+v=z_{p} \\
x=\left[\begin{array}{c}
x_{p} \\
x_{a}
\end{array}\right], y=\left[\begin{array}{c}
y_{p} \\
f
\end{array}\right], w=\left[\begin{array}{c}
w_{f} \\
w_{u}
\end{array}\right], A=\left[\begin{array}{cc}
A_{p} & B_{p} C_{a} \\
0 & A_{a}
\end{array}\right], D=\left[\begin{array}{cc}
B_{p} & 0 \\
0 & B_{a}
\end{array}\right], \\
W=\left[\begin{array}{cc}
W_{f} & U_{f u} \\
U_{f u}^{*} & W_{u}
\end{array}\right], C=\left[\begin{array}{cc}
c_{p} & 0 \\
0 & C_{a}
\end{array}\right], B=\left[\begin{array}{c}
0 \\
B_{a}
\end{array}\right], M^{T}=\left[\begin{array}{c}
M_{p}^{T} \\
0
\end{array}\right]
\end{gathered}
$$

where $\mathrm{f}=\mathrm{C}_{\mathrm{a}} \mathrm{x}_{\mathrm{a}},\left(\mathrm{A}_{\mathrm{a}}, \mathrm{C}_{\mathrm{a}}\right)$ is observable, and $\operatorname{Re}\left[\lambda_{\mathrm{i}}\left(\mathrm{A}_{\mathrm{a}}\right)\right]<0, \quad \mathrm{i}=1,2, \cdots \mathrm{n}_{\mathrm{a}} \cdot\left(\mathrm{A}_{\mathrm{a}}, \mathrm{B}_{\mathrm{a}}\right)$ is controllable.

First note that since $x_{p}$ is observable from $y_{p}$, (i.e., $\left(A_{p}, C_{p}\right)$ is observable) and $x_{a}$ is observable from $f$ (i.e., $\left(A_{a}, C_{a}\right)$ is observable) then from the definitions $(2.5) \times$ must be observable from $y$, that is:

$$
(\mathrm{A}, \mathrm{C}) \text { is observable }
$$

Also note that the actuator dynamics are assumed stable, so that the system (2.1) has not been augmented with any unstable states. Therefore, detectability of $\left(A_{p}, M_{p}\right)$ together with stable $A_{a}$ yields

(A,M) detectable. 
Finally, Theorem 1 states the conditions for controllability of the system (2.1) augmented with actuator dynamics (2.5). Proof of the theorem is contained in the Appendix.

Theorem 1

Consider the controllable system

$$
\begin{gathered}
\dot{x}_{p}=A_{p} x_{p}+B_{p}\left(f+w_{f}\right), \quad\left(A_{p}, B_{p}\right) \text { controllable } \\
x_{p} \in R^{n x_{p}}
\end{gathered}
$$

augmented with controllable and observable actuator dynamics of arbitrary order

$$
\begin{gathered}
\dot{x}_{a}=A_{a} x_{a}+B_{a}\left(u+w_{u}\right), \quad\left(A_{a}, B_{a}\right) \text { controllable } \\
f=C_{a} x_{a}, \quad\left(A_{a}, C_{a}\right) \text { observable, } \quad x_{a} \in R^{n x_{a}}, \quad f \in R^{n u}
\end{gathered}
$$

to form the composite system

$$
\begin{gathered}
\dot{x}=A x+D w+B u \\
A=\left[\begin{array}{cc}
A_{p} & B_{p} C_{a} \\
0 & A_{a}
\end{array}\right], \quad D=\left[\begin{array}{cc}
B_{p} & 0 \\
0 & B_{a}
\end{array}\right], \quad B=\left[\begin{array}{c}
0 \\
B_{a}
\end{array}\right], \quad x=\left[\begin{array}{c}
x_{p} \\
x_{a}
\end{array}\right], \quad w=\left[\begin{array}{c}
w_{f} \\
w_{u}
\end{array}\right)
\end{gathered}
$$

The system sıates $\mathrm{x}_{\mathrm{p}}$ are controllable from $\mathrm{u}(\mathrm{t})$ if the number of poles minus the number of zeros is the same for each individual actuator's transfer function.

Remark 1: Note that full controllability of the augmented-system state vector $\mathrm{x}$ is not guaranteed under the conditions of the theorem.

Remark 2: The conditions of the theorem are always met for first order dynamic actuators, (assuming no direct input/output "feedthrough" for the actuators), since each actuator will have one pole and no zeros. 
Remark 3: As long as the original system states $x_{p}$ are controllable through some minimum set of actuators meeting the criteria of the theorem above, then controllability of $\mathrm{x}_{\mathrm{p}}$ will be maintained with the addition of actuators of any order and any number of transfer zeros.

Remark 4: Finally, note that the usefulness of the theorem stems from the fact that by meeting certain mildly restrictive conditions, the actuator dynamics can be guaranteed not to destroy controllability of the original system states, regardless of the pole/zero locations of the plant.

\subsection{Adding Sensor Dynamics}

Next the system (2.5) is augmented to include stable, observable, controllable sensor dynamics of arbitrary order.

$$
\begin{gathered}
\dot{x}_{s}=A_{s} x_{s}+B_{s}\left(M_{p} x_{p}+v_{i n}\right), \quad\left(A_{s}, B_{s}\right) \text { controllable } \\
z=C_{s} x_{s}+v_{\text {out }}, \quad\left(A_{s}, C_{s}\right) \text { is observable, } \quad x_{s} \in R^{n_{s}} \\
\operatorname{Re}\left[\lambda_{i}\left(A_{s}\right)\right]<0, \quad i=\left\{1,2, \cdots n_{s}\right\}
\end{gathered}
$$

Figure 2.2 presents schematic representations for actuator models of varying degrees of complexity; Figure $2.2 \mathrm{a}$ represents the non-dynamic sensor, while Figure $2.2 \mathrm{~b}$ represents the general model for a dynamic sensor with white noise. Note from both eqn (2.8) and Figure $2.2 \mathrm{~b}$ that (similarly to the case of actuator dynamics), adding sensor dynamics leads to the possibility of both sensor input noise and sensor output noise. The $\mathrm{i}_{\mathrm{th}}$ sensor's input noise $\left(v_{i n}\right)_{i}$ is filtered by the dynamics of the $i_{h h}$ sensor, while the output noise $\left(v_{\text {out }}\right)_{i}$ is purely additive with the sensor output. Both types of noise are assumed possible in our development. 


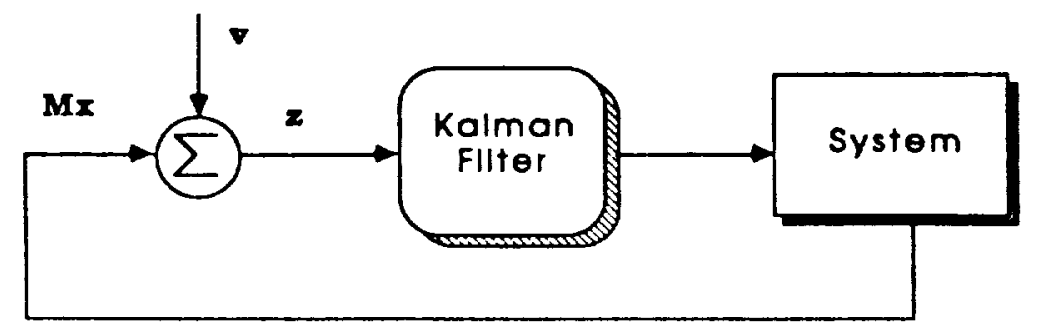

Figure 2.2a

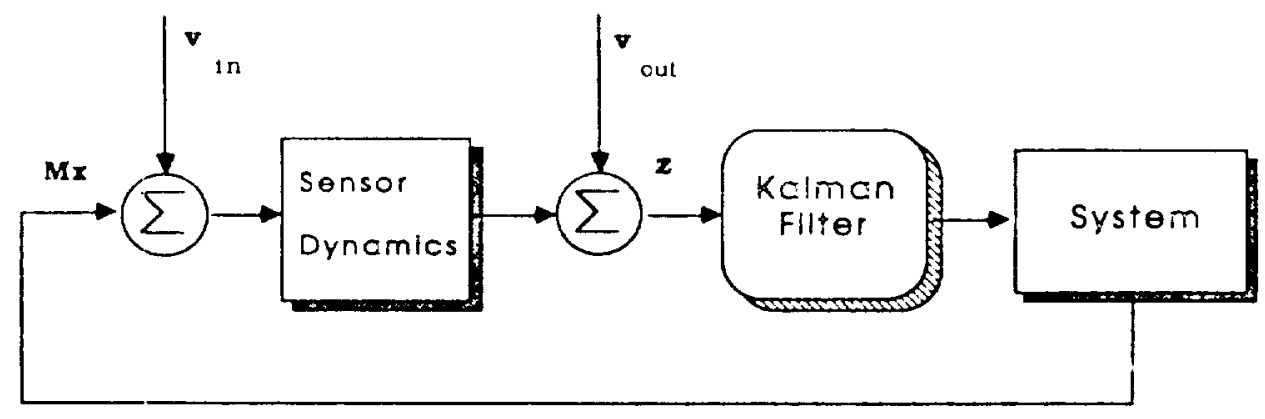

Figure 2.2b

Figure 2.2: Sensor Models

225 
The fully augmented system equations have the following form:

$$
\begin{aligned}
& \dot{x}=A x+B u+D w \\
& y=C x \\
& z=M x+v \\
& x^{\mathrm{T}}=\left[\mathrm{x}_{\mathrm{p}}^{\mathrm{T}}, \mathrm{x}_{\mathrm{a}}^{\mathrm{T}}, \mathrm{x}_{\mathrm{s}}^{\mathrm{T}}\right], \quad y^{\mathrm{T}}=\left[\mathrm{y}_{\mathrm{p}}^{\mathrm{T}}, \mathrm{f}^{\mathrm{T}}\right], w^{\mathrm{T}}=\left[\mathrm{w}_{\mathrm{f}}^{\mathrm{T}}, \mathrm{w}_{\mathrm{u}}^{\mathrm{T}}, \mathrm{v}_{\text {in }}^{\mathrm{T}}\right], \quad v=\mathrm{v}_{\text {out }} \\
& \mathrm{D}=\left[\begin{array}{ccc}
\mathrm{B}_{\mathrm{p}} & 0 & 0 \\
0 & \mathrm{~B}_{\mathrm{a}} & 0 \\
0 & 0 & \mathrm{~B}_{\mathrm{s}}
\end{array}\right], A=\left[\begin{array}{ccc}
\mathrm{A}_{\mathrm{p}} & \mathrm{B}_{\mathrm{p}} \mathrm{C}_{\mathrm{a}} & 0 \\
0 & \mathrm{~A}_{\mathrm{a}} & 0 \\
\mathrm{~B}_{\mathrm{s}} \mathrm{M}_{\mathrm{p}} & 0 & \mathrm{~A}_{\mathrm{s}}
\end{array}\right], C=\left[\begin{array}{ccc}
\mathrm{C}_{\mathrm{p}} & 0 & 0 \\
0 & \mathrm{C}_{\mathrm{a}} & 0
\end{array}\right] \text { or } C=\left[\begin{array}{ll}
\mathrm{C} & 0
\end{array}\right] \\
& B=\left[\begin{array}{c}
0 \\
\mathrm{~B}_{\mathrm{a}} \\
0
\end{array}\right], V=\mathrm{V}_{\text {out }}, W=\left[\begin{array}{cc}
\mathrm{W} & \mathrm{U} \\
\mathrm{U}^{*} & \mathrm{~V}_{\text {in }}
\end{array}\right], M=\left[\begin{array}{lll}
0 & 0 & \mathrm{C}_{\mathrm{s}}
\end{array}\right]
\end{aligned}
$$

The response $y_{p}(s)$ of the plant to the input $f(s)$ is given by

$$
y_{p}(s)=H_{p}(s) f(s)
$$

where

$$
H_{p}(s)=C_{p}\left(s I-A_{p}\right)^{-1} B_{p} .
$$

is the plant transfer function. The response $M x(s)$ of the actuator/plant system (2.9) to the input $u(s)$ is given by

$$
M x(s)=H(s) u(s),
$$

where

$$
H(s)=M(s I-A)^{-1} B .
$$

Finally, the response $z(s)$ of the sensors to an input $M x(s)$ is given by 


$$
z(s)=H_{s}(s) M x(s),
$$

where

$$
\mathrm{H}_{\mathrm{s}}(\mathrm{s})=\mathrm{C}_{\mathrm{s}}\left(\mathrm{sI}-\mathrm{A}_{\mathrm{s}}\right)^{-1} \mathrm{~B}_{\mathrm{s}}
$$

is the transfer function for the sensor dynamics. Minimal systems are controllable and observable. Thus, given minimality of the plant/actuator system $[(\mathrm{A}, \mathrm{B})$ controllable and $(A, M)$ observable], then measurability of the full augmented system is guaranteed $[(A, M)$ observable $]$ if there are no pole/zero cancellations between $\mathrm{H}(\mathrm{s})$ and $\mathrm{H}_{\mathrm{s}}(\mathrm{s})$.

\subsection{Defining the Cost Function}

With the properties of the augmented system established, optimal control design for the augmented system is now considered. Recall that the standard LQG cost function (2.3) for the unaugmented system (2.1) includes a penalty on the output regulation error $y(t)$, as well as a penalty on the control energy $u(t)$. However, in the augmented system (2.5), while the actuator command is given by $\mathrm{u}(\mathrm{t})$, the actuator response $\mathrm{f}(\mathrm{t})$ (contained in the augmented output vector $y)$ is distinct from $u(t)$ due to actuator dynamics. A true measure of control energy is more appropriately stated in terms of a weighted sum of the variaices of $f(t)$ rather than of $u(t)$. It can readily be shown, however, that even in the presence of a weighting on the actuator outputs, $f(t)$, some nonzero weightirig on the actuator inputs $u(t)$ is necessary to avoid an infinite gain solution to the optimization problem. For this reason, and in view of the relation of $f(t)$ to the design goals as discussed above, minimization of cost functions of the form

$$
V=E_{\infty}\left[\|y(t)\|_{Q}^{2}+\|u(t)\|_{R}^{2}\right]
$$

and 


$$
\mathrm{Q}=\operatorname{diag}\left[\mathrm{Q}_{\mathrm{o}}, \mathrm{Q}_{\mathrm{a}}\right], \quad \mathrm{Q}>0
$$

provides a stable optimal closed-loop solution.

\subsection{SELECTION OF DYNAMIC SENSORS AND ACTUATORS}

\subsection{Closed-Loop Input/Output Cost Analysis}

In order to write the expressions for the closed-loop input and output costs, it is first necessary to put the fully augmented system, under closed loop steady-state optimal state-estimate feedback control, in the following state space form:

$$
\begin{gathered}
\dot{x}(t)=\mathbf{A x}(\mathrm{t})+\mathrm{D}_{w}(\mathrm{t}) \\
\mathbf{y}(\mathrm{t})=\mathrm{Cx}(\mathrm{t}) \\
V=E_{\infty} V_{\mathrm{o}}(\mathrm{t}), V_{\mathrm{o}}(\mathrm{t})=\mathbf{y}^{*}(\mathrm{t}) \mathbf{Q} \mathbf{y}(\mathrm{t}),
\end{gathered}
$$

where

$$
\begin{gathered}
\mathbf{x}^{\mathrm{T}}=\left[x^{\mathrm{T}}, x_{c}^{\mathrm{T}}\right], \mathbf{y}^{\mathrm{T}}=[y]^{\mathrm{T}} \quad \mathbf{w}^{\mathrm{T}}=\left[w^{\mathrm{T}}, v^{\mathrm{T}}\right] \\
\mathbf{A}=\left[\begin{array}{cc}
A & B G \\
F M & A+B G-F M
\end{array}\right], \mathbf{D}=\left[\begin{array}{ll}
D & 0 \\
0 & F
\end{array}\right], \mathbf{C}=\left[\begin{array}{ll}
C & 0 \\
0 & G
\end{array}\right], \mathbf{Q}=\left[\begin{array}{ll}
Q & 0 \\
0 & R
\end{array}\right], \mathbf{W}=\left[\begin{array}{cc}
W & U \\
U^{*} & V
\end{array}\right] \\
G=-R^{-1} B^{\mathrm{T}} K, 0=K A+A^{\mathrm{T}} K-K B R^{-1} B^{\mathrm{T}} K+C^{\mathrm{T}} Q C \\
F=\left[P M^{\mathrm{T}}+D U\right] V^{-1}, 0=\left[A-D U V^{-1} M\right] P+P\left[A-D U V^{-1} M\right]^{\mathrm{T}} \\
-P M^{\mathrm{T}} V^{-1} M P+D W D^{\mathrm{T}}-D U V^{-1} U^{\mathrm{T}} D^{\mathrm{T}}
\end{gathered}
$$

For the system (3.1) the output costs $V_{1}^{y}$, defined by 


$$
V_{1}^{y}=(1 / 2)\left\{E_{\infty}\left(\partial V_{\delta} \partial y_{i}\right) y_{i}\right\}
$$

are calculated as follows [2]

$$
V_{i}^{y}=\left[C X C^{T} Q_{i i}\right.
$$

where $\mathrm{X}$ is the steady state covariance satisfying

$$
0=A X+X A^{T}+D W D^{T}
$$

and where the output costs satisfy the cost decomposition property

$$
\sum_{i=1}^{n_{y}} V_{i}^{y}=V .
$$

The input costs are defined by

$$
\mathrm{V}_{\mathrm{i}}^{\mathrm{w}}=(1 / 2)\left\{E_{\infty}\left(\partial V_{\mathrm{o}} / \partial \mathrm{w}_{\mathrm{i}}\right) \mathrm{w}_{\mathrm{i}}\right\}
$$

and are found from [2]

$$
\mathrm{V}_{\mathrm{i}}^{\mathrm{w}}=\left[\mathrm{D}^{\mathrm{T}} \mathrm{SDW}\right]_{\mathrm{ii}}
$$

where $\mathrm{S}$ satisfies

$$
0=A^{T} S+S A+C^{T} Q C
$$

and where the input costs also satisfy the cost decomposition property

$$
\stackrel{\mathrm{n}}{\mathrm{w}}^{\mathrm{N}} \mathrm{v}_{\mathrm{i}}^{\mathrm{w}}=V
$$

The input and output costs represent the in situ contributions that the noise inputs and the system outputs make in the cost function. We may also wish to know the amount by which the cost function will be reduced if a noise input is eliminated. This amount, $\Delta V_{i}{ }^{w}$, is defined as

\section{9}




$$
\Delta \mathrm{V}_{\mathrm{i}}^{\mathrm{w}}=V-\mathrm{V}_{\mathrm{Ri}}
$$

where $\mathrm{V}_{\mathrm{Ri}}$ is the value of the cost function after the $\mathrm{i}_{\mathrm{th}}$ noise input is eliminated, (but the controller is not redesigned) and $\Delta V_{i}^{w}$ is the cost reduction due to eliminating $w_{i}$. A positive value for $\Delta \mathrm{V}_{\mathrm{i}}^{w}$ indicates that elimination of the $\mathrm{i}_{\mathrm{th}}$ input will reduce the cost, while negative $\Delta \mathrm{V}_{\mathrm{i}}^{\mathrm{w}}$ indicates that a cost increase will follow noise elimination. It was shown in [1] that the $\Delta V_{i}^{w}$ may be positive or negative in the presence of noise correlation. Partitioning the matrices $\mathrm{W}$ and $\mathrm{D}$ facilitates direct solution for the cost reduction [2], yielding

$$
\Delta \mathrm{V}_{\mathrm{i}}^{\mathrm{w}}=2 \mathrm{~V}_{\mathrm{i}}^{\mathrm{w}}-\mathrm{d}_{\mathrm{i}}^{*} S \mathrm{~d}_{\mathrm{i}} \mathrm{W}_{\mathrm{ii}}
$$

The closed-loop covariance $\mathrm{X}$ may be written

$$
\mathrm{X}=\left[\begin{array}{cc}
P+N & N \\
N & N
\end{array}\right]
$$

where $P$ satisfies eqn $(3.1 \mathrm{~g})$ and where $N$ satisfies:

$$
0=N(A+B G)^{\mathbf{T}}+(A+B G) N+F V F^{\mathrm{T}}
$$

Also, $\mathrm{S}$ has the following form

$$
\mathrm{S}=\left[\begin{array}{cc}
K+L & -L \\
-L & L
\end{array}\right]
$$

where $K$ satisfies eqn (3.1f) and where $L$ satisfies

$$
0=L(A-F M)+(A-F M)^{\mathrm{T}} L+G^{\mathrm{T}} \mathrm{R} G
$$

For notational convenience the steady state covariance $\mathrm{X}$ is partitioned as follows: 


$$
X=[P+N]=\left[\begin{array}{lll}
\mathrm{X}_{\mathrm{p}} & \mathrm{X}_{12} & \mathrm{X}_{13} \\
\mathrm{X}_{12}^{\mathrm{T}} & \mathrm{X}_{\mathrm{a}} & \mathrm{X}_{23} \\
\mathrm{X}_{13}^{\mathrm{T}} & \mathrm{X}_{23}^{\mathrm{T}} & \mathrm{X}_{\mathrm{S}}
\end{array}\right]
$$

Using the notation of (3.10) and the special structure of the closed-loop system matrices in eqn (3.13) we write the following expressions for the output costs

$$
\begin{gathered}
\mathrm{V}_{\mathrm{i}}^{\mathrm{y}_{\mathrm{p}}}=\left[\mathrm{C}_{\mathrm{p}} \mathrm{X}_{\mathrm{p}} \mathrm{C}_{\mathrm{p}}^{\mathrm{T}} \mathrm{Q}_{\mathrm{p}}\right]_{\mathrm{ii}} \quad \mathrm{i}=1, \cdots \mathrm{ny}_{\mathrm{p}} \\
\mathrm{V}_{\mathrm{i}}^{\mathrm{f}}=\left[\mathrm{C}_{\mathrm{a}} \mathrm{X}_{\mathrm{a}} \mathrm{C}_{\mathrm{a}}^{\mathrm{T}} \mathrm{Q}_{\mathrm{a}}\right]_{\mathrm{ii}} \quad \mathrm{i}=1, \cdots \mathrm{nu} \\
\mathrm{V}_{\mathrm{i}}^{\mathrm{u}}=\left[G N G^{\mathrm{T}} \mathrm{R}\right]_{\mathrm{ii}} \quad \mathrm{i}=1, \mathrm{nu}
\end{gathered}
$$

and for the input costs

$$
\begin{aligned}
& \mathrm{V}_{\mathrm{i}}^{\mathrm{w}}=\left[D^{\mathrm{T}}(K+L) D W\right]_{\mathrm{ii}} \quad \mathrm{i}=1, \cdots \mathrm{nw} \\
& \mathrm{V}_{\mathrm{i}}^{\mathrm{v}_{\mathrm{in}}}=\left[D^{\mathrm{T}}(K+L) D W\right]_{\mathrm{nw}+\mathrm{i}, \mathrm{nw}+\mathrm{i}} \quad \mathrm{i}=1, \cdots \mathrm{nz} \\
& \mathrm{V}_{\mathrm{i}}^{\mathrm{v}_{\text {our }}}=\left[F^{\mathrm{T}} L F V\right]_{\mathrm{ii}} \quad \mathrm{i}=1, \cdots \mathrm{nz}
\end{aligned}
$$

and the input cost reductions

$$
\begin{array}{cc}
\Delta \mathrm{V}_{\mathrm{i}}^{\mathrm{w}}=\left[D^{\mathrm{T}}(K+L) D W-D^{\mathrm{T}} L F U^{\mathrm{T}}\right]_{\mathrm{ii}} \quad \mathrm{i}=1, \cdots \mathrm{nw} \\
\Delta \mathrm{V}_{\mathrm{i}}^{\mathrm{v}_{\mathrm{in}}}=\left[D^{\mathrm{T}}(K+L) D W-D^{\mathrm{T}} L F U^{\mathrm{T}}\right]_{\mathrm{nw}+\mathrm{i}, n \mathrm{w}+\mathrm{i}} \quad \mathrm{i}=1, \cdots \mathrm{nz} \\
\Delta \mathrm{V}_{\mathrm{i}}^{\text {vour }}=\left[F^{\mathrm{T}} L F V-F^{\mathrm{T}} L F V-F^{\mathrm{T}} L B U\right]_{\mathrm{ii}} . \quad \mathrm{i}=1, \cdots \mathrm{nz}
\end{array}
$$




\subsection{Dynamic Actuator Effectiveness Values}

Now that the closed-loop input and output costs have been determined for systems with dynamic sensors and actuators, it remains to use the CIOCA results to define expressions which reflect the effectiveness of each sensor and actuator in the cost function. This section defines the effectiveness values for dynamic actuators. The approach taken in [1] and [2] for non-dynamic actuators was to subtract the contribution the $\mathrm{i}_{\mathrm{th}}$ actuator's noise in the cost function from the contribution of its control signal, and to label this difference the "effectiveness" of the $\mathrm{i}_{\mathrm{th}}$ actuator, $\mathrm{V}_{\mathrm{i}}^{\text {act }}$. That is,

$$
V_{i}^{\text {act }}=V_{i}^{u}-\Delta V_{i}^{w}
$$

This subtracts the "bad" from the "good" contributions of the actuator to measure its effectiveness. The results of applying (3.14) to sensor and actuator selection for a range of small and large scale examples in [2], [3], [4], [17] and [18] have demonstrated the utility of this approach.

Extendirg the definition (3.14) for applicability to systems with dynamic aciuators, we proceed as follows. In (3.1) there are two noise sources associated with each actuator: command noise, $w_{u}$, which is filtered by the actuator dynamics; and output noise, $w_{f}$, which is additive with the actuator output. Thus, the noise contribution associated with the $i_{\text {ch }}$ actuator is given by the sum of $\Delta V_{i}^{w_{*}}$ and $\Delta V_{i}^{w_{t}}$.

The beneficial control cost for each actuator is not immediately evident. First, recall that it is the actuator output $\mathrm{f}(\mathrm{t})$, not its input $\mathrm{u}(\mathrm{t})$, which drives the system. Next, note that the contribution of the $\mathrm{i}_{\mathrm{th}}$ actuator's output in the cost function, $\mathrm{V}_{\mathrm{i}}^{\mathrm{f}}$, includes the effects of noise $w_{u i}$. That is, even in the open loop $(u \equiv 0), V_{i}^{f} \neq 0$ for $\left[W_{u}\right]_{i i}>0$ with dynamics. Hence, to define the beneficial (control) portion of $V_{i}^{f}$ it is necessary to subtract the portion of $V_{i}^{f}$ which is due to noise. This can not be accomplished exactly,

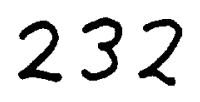


since the actuator command $u(t)$ and the command noise $w_{u}(\tau)$ are correlated for $t>\tau$. An approximation is obtained, however, by solving for $V_{i}^{f}$ when $u \equiv 0$ (that is, in the open loop). We define the contribution of $w_{u i}$ to $V_{i}^{f}$ and the contribution of $u_{i}$ to $V_{i}^{f}$ as follows, using the open loop covariance of the actuator states $\underline{X}_{\mathrm{a}}$ :

$$
\left[V_{i}^{f}\right]^{w}=\left[C_{a} X_{a} C_{a}^{T} Q_{a}\right]_{i i}
$$

and

$$
\left[V_{i}^{f}\right]^{u}=V_{i}^{f}-\left[V_{i}^{f}\right]^{w}=\left[C_{a}\left(X_{a}-\underline{X}_{a}\right) C_{a}^{T} Q_{a}\right]_{i i}
$$

where $\underline{X}_{\mathrm{a}}$ solves

$$
0=A_{a} X_{a}+\underline{X}_{a} A_{a}^{T}+B_{a} W_{u} B_{a}^{T}
$$

Finally, the input costs and the decomposition of the output cost $V_{i}^{f}$ are combined in an effectiveness formula for dynamic actuators which is motivated by the results of [1] and [2]:

$$
V_{i}^{a c t}=\left[V_{i}^{f}\right]^{u}-\Delta V_{i}^{w f}-\Delta V_{i}^{w_{a}}
$$

Note that in the absence of command input noise, $\left[\mathrm{V}_{\mathrm{i}}^{\mathrm{f}}\right]^{\mathrm{w}}$ and $\mathrm{V}_{\mathrm{i}}^{\mathrm{wa}_{\mathrm{a}}}$ are both zero. Also, in the absence of actuator dynamics, $f_{i}(t)$ is equivalent to $u_{i}(t)$. Thus the expression (3.16) reduces to the original effectiveness formula of [1] in the absence of actuator dynamics. Note also that (3.16) is applicable whether or not the actuator noise signals are correlated with other noise sources, and it is applicable to systems with actuator dynamics of arbitrary order.

\subsection{Dynamic Sensor Effectiveness Values}

Unlike the actuator noise, (which has a direct path to the output, independently of the conrollers influence) the noise associated with sensors reaches the system only 
through the controller. Since the gains in the Kalman filter of the LQG controller represent an optimal trade-off of each sensor's (beneficial) measurement information versus the (performance degrading) impact of its noise, then a $\Delta V_{i}^{v}$ of large magnitude is indicative of a highly effective sensor. That is, the fact that a sensor's noise is being allowed to heavily affect the cost means that its measurement information is even more critical to performance. For this reason, the following effectiveness formula for nondynamic sensors, generalized to accommodate the possibility of noise correlation, was presented in [1]:

$$
\mathrm{V}_{\mathrm{i}}^{\mathrm{sen}} \triangleq\left|\Delta \mathrm{V}_{\mathrm{i}}^{\mathrm{v}}\right| .
$$

For dynamic sensors there are two possible noise inputs associated with each sensor. As in the non-dynamic case, both noise inputs reach the system dynamics through the Kalman filter. Thus a straightforward extension of (3.17) to dynamic sensors is

$$
V_{i}^{\text {sen }}=\left|\Delta V_{i}^{v_{\text {id }}}\right|+\left|\Delta V_{i}^{\text {vour }}\right|
$$

Note that this formula is applicable in the presence of sensor dynamics of arbitrary order, and applies whether or not any of the noise sources are correlated with one another.

This section concludes with the suggestion that (3.16) and (3.18) provide effective measures of tha contribution of each actuator and sensor in a closed loop optimal LQG control (with sensor and actuator dynamics properly included).

\subsection{SELECTION OF DYNAMIC ACTUATORS FOR SCOLE}

In this section the actuator selection problem is solved for a model of NASA's SCOLE (Spacecraft Control Laboratory Experiment) system. The SCOLE configuration consists of a flexible antenna suspended from the Space Shuttle cargo bay by a $130 \mathrm{ft}$.

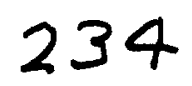


flexible beam (see Figure 4.6). The effectiveness values for proof mass actuators (PMA's) located along the beam are calculated and plotted versus position for both dynamic and non-dynamic actuators in order to evaluate the dynamic actuator selection method and to determine the effect of actuator dynamics on our results.

\subsection{PROBLEM DEFINITION}

A certain 2-dimensional SCOLE model includes four flexible modes and no rigid body modes [15-18]. Approximate open-loop mode shapes for the four flexible modes are presented in Figure 4.7, and the results of an open loop modal cost analysis are presented in Table 4.2. A detailed discussion of the model development is given in [16] and [18]. The two sensors retained in the model (using the CIOCA method of selection for non-dynamic sensors) are angular position and rate measurements located at the center of mass of the reflector [18]. Since there are no accelerometers presents, then the sensor and actuator noise is uncorrelated. Noise intensity data for the sensors is given in Table 4.3.

The set of admissible actuators includes both a control moment gyro (CMG) located at the reflector center of mass and a set of PMAs distributed along the flexible beam. The actuator selection problem is to determine the optimal location for two PMA devices along the beam. To this end, the admissible set of PMAs was defined as 20 actuators spaced at distances of 6.25 feet apart on the 130 -foot beam from a point 10.75 feet above the shuttle end of the beam to a point 129.5 feet from the shuttle. The PMA locations are

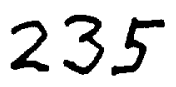




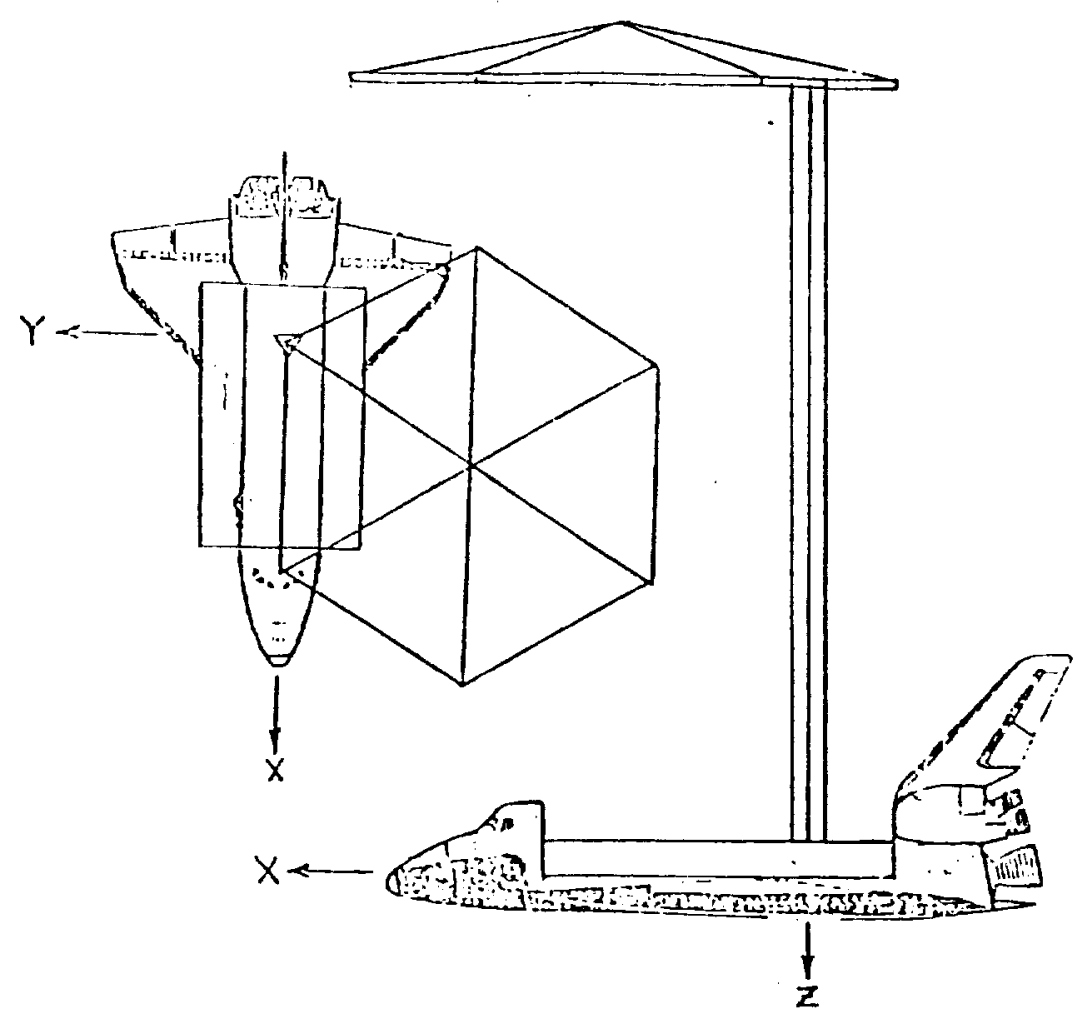

Figure 1.1: SCOLE Configuration

4.6

236 


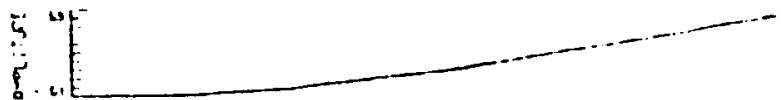

Pitch In milisg mude \# 1. Frequency $=.29 \mathrm{~Hz}$

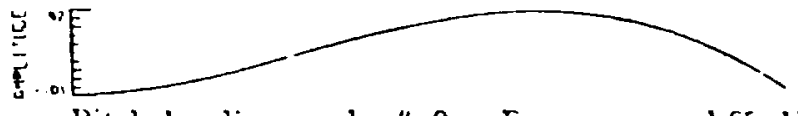

Pitch lending inde $\# 2$ Frequency $=1.65 \mathrm{~Hz}$
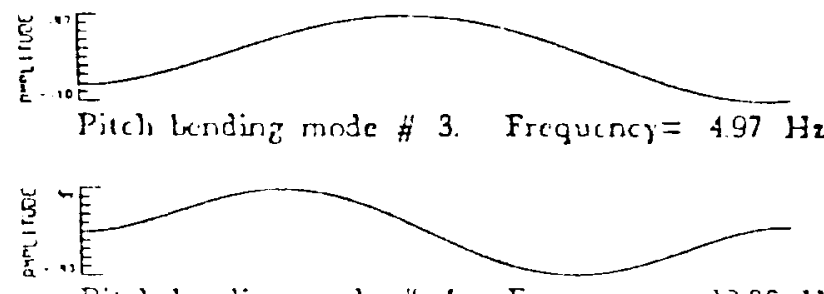

Pifch lending roode 4 \& Frequency $=12.36 \mathrm{~Hz}$
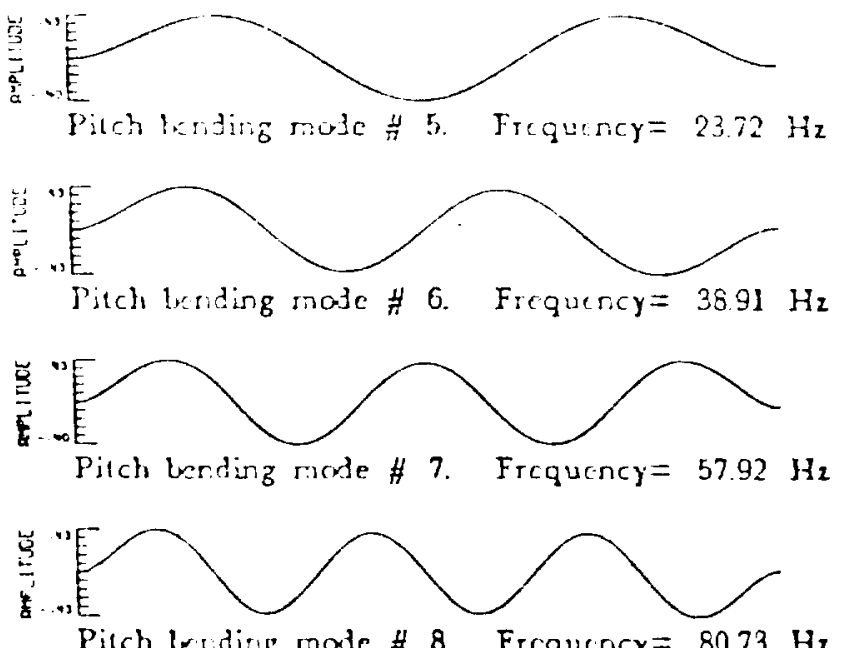

Figure 1.4 Fexible Pich-Direction Mode Shapes for 2 Dimencineal SCOLE $\because 7$ 


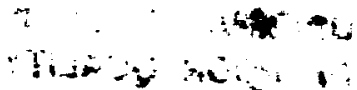

\begin{tabular}{|c|c|c|c|}
\hline Mode" & Frequency $(\mathrm{Hz})$ & Moxial Cost & Percent Toul \\
\hline 1 & $.289 E+00$ & $.5+7 E+01$ & $.466 \mathrm{E}+1) 2$ \\
\hline 2 & $.16+E+(1)$ & $626 E+01$ & $.533 \mathrm{E}+02$ \\
\hline 3 & $.497 \mathrm{E}+01$ & $10.5 \mathrm{E} \cdot 01$ & $895 \mathrm{E}-01$ \\
\hline 4 & $124 E+12$ & $180 \mathrm{E} \cdot 04$ & $.153 \mathrm{E} \cdot 03$ \\
\hline 5 & $237 E+02$ & $201 \mathrm{E}-06$ & $.171 \mathrm{E} \cdot 05$ \\
\hline 6 & $.389 E+n 2$ & $.692 \mathrm{E}-08$ & $.590 \mathrm{E} \cdot 07$ \\
\hline 7 & $580 E+1) 2$ & $470 \mathrm{E}-109$ & . ARUE-08 \\
\hline 8 & SUE: +2 & $5 \%, 510$ & 4.1E. (Y) \\
\hline 0 & $m<E+n 3$ & 7.4KE-11 & TSSE 10 \\
\hline 10 & $.12, E+1) 3$ & $142 E-11$ & $121 E \cdot 10$ \\
\hline 11 & $175 E+03$ & $322 \mathrm{E}-12$ & $.27+E-11$ \\
\hline 12 & $2: 5 E+03$ & HAE.13 & $.72: E \cdot 12$ \\
\hline 13 & $35 Y E+1) 3$ & $.215 E-13$ & $207 E-12$ \\
\hline
\end{tabular}

Table 4.3 Noise Specitications for SCOLE Acutators and Sensors

\begin{tabular}{|c|c|c|c|c|}
\hline \multirow[b]{3}{*}{$T ; p e$} & \multirow{3}{*}{$\begin{array}{c}\text { Dynamic } \\
\text { Runge }\end{array}$} & \multirow{3}{*}{$\begin{array}{l}\text { Noise } \\
\text { lnionsity }\end{array}$} & \multicolumn{2}{|c|}{ Acilistors } \\
\hline & & & & Soive \\
\hline & & & Type & lotensily \\
\hline PMA & $10 \mathrm{lb}$ & $0001(16)^{2}$ & Accelerometers & $v_{0}=(x)=5\left(\mathrm{deg}^{2} \mathrm{sec}^{2}\right)^{2}$ \\
\hline C.MG & $10^{5} \mathrm{rt}-\mathrm{ib}$ & $10,(100)(11-1 b)^{2}$ & Angulis Postion & $10^{-4}(\operatorname{deg})^{2}$ \\
\hline & & & & (ons $/ \mathrm{deg} / \mathrm{sec})^{2}$ \\
\hline
\end{tabular}


thus selected by evaluating the relative effectiveness of each of the 20 PMA locations.

\subsection{RESULTS FOR NON-DYNAMIC ACTUATORS}

The PMA selection problem for non-dynamic actuators was solved first, for later comparison with the dynamic actuator selection results. In all cases (dynamic and nondynamic) the actuator effectiveness values are calculated following controller design which achieves a specified output variance and minimizes the amount by which the actuators exceed their specified variances. This type of controller is designed by an iterative selection of the control and output weights using the Output Variance Assignment (OVA) algorithm (DeLorenzo and Skelton, [3]). The variance specification for each actuator was equal to 10 times the intensity of its noise (see Table 4.3).

The actuator effectiveness values based upon standard Closed Loop Input/Output Cost Analysis (CIOCA) [2] for non-dynamic actuators are presented in Figure 4.8. The figure portrays PMA effectiveness results for four different controllers, each achieving a different steady-state line-of-sight (LOS) error variance. The results provide a vivid illustration of how the controller objectives can profoundly influence the actuator selection results. For lower gain controllers (lower LOS error) the theory determines that the upper tip is the most desirable PMA location. However, as the gain increases (controller designed for smaller LOS error) the center of the beam becomes the optimal location.

The results of Figure 4.8 are readily explained via modal analysis. The mode shape figures for the four flexible modes retained in the 2-dimensional SCOLE model were

presented in Figure 4.7. Recall that mode \#1, which accounts for 46.6 percent of the open loop modal cost, has a maximum amplitude at the reflector-end tip of the beam (i.e., at $130 \mathrm{ft}$.). Mode number $\# 2$, which accounts for 53.3 percent of the open loop modal

\section{9}




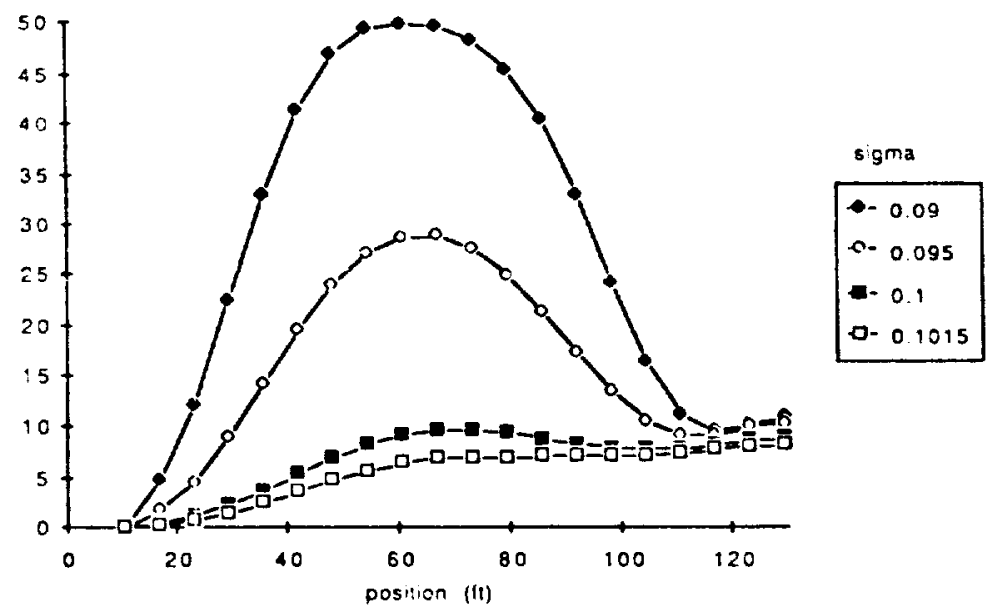

4. 8

240 
cost, has a maximum amplitude near the $90 \mathrm{ft}$. point. And mode \#3, which accounts for only approximately 0.1 percent of the open loop modal cost, has a peak amplitude near the center of the beam.

Next note from Figure 4.8 that as the gain is increased in order to achieve a smaller steady state LOS error variance, the most effective location for PMAs shifts from the tip of the beam to the midpoint. This corresponds to a shift from the peak of mode \#1 to the peak of mode \#3. The shift occurs even though with higher gain the noise in the PMAs near the beam midpoint becomes the most detrimental to performance (Figure 4.9). In fact, Figure 4.9 indicates the reason for the shift in optimal PMA location: with higher gain the third mode becomes the least damped by the control of the CMG, and becomes therefore a significant mode to be controlled by the PMAs. Figure 4.10 and Table 4.4 indicate the motion of the closed-loop eigenvalues from their open loop locations under varying levels of gain (output performance).

Since the control cost of each PMA $\left(V_{i}^{u}=E_{\infty} r_{i} u_{i}{ }^{2}\right)$ is equal to its effectiveness value $\mathrm{V}_{\mathrm{i}}^{\text {act }}$ minus the cost contribution of its noise, $\mathrm{V}_{\mathrm{i}}{ }^{\mathrm{w}}$, then it is clear from Figures 4.8 and 4.9 that the PMAs are being used primarily to control mode \#3 (i.e., near the middle of the beam). However mode \#3 is the most lightly damped mode in the closed loop. This is true in spite of the fact that in all cases the input variances of both the CMG and PMAs, when normalized by their variance specifications, are of like order of magnitude (see Figure 4.11).

The results demonstrate the interesting result that while the PMAs are being used at a level similar to the CMGs (in relation to their specified variance levels), they nontheless make a small contribution to the closed-loop modal damping. This claim is verified by deleting all PMAs from the system and again using OVA to achieve a specified LOS error of 0.1 ( $\operatorname{arcsec})^{2}$, and comparing the resulting closed-loop modal and 


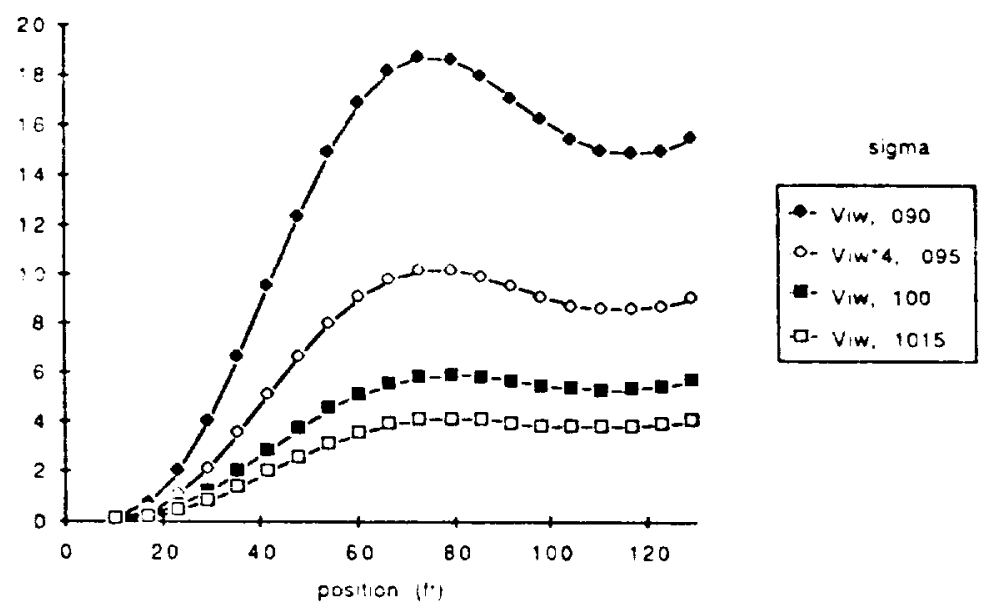




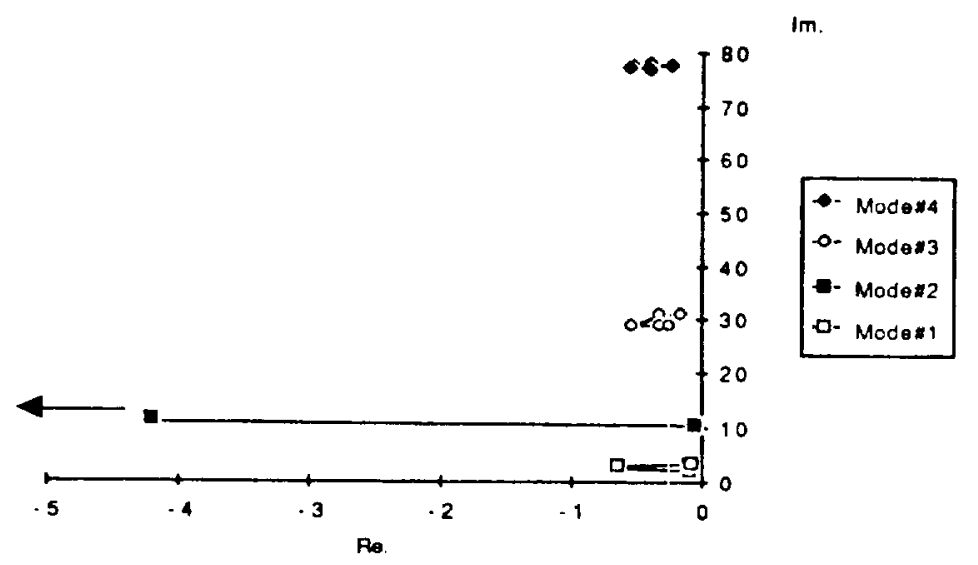




\section{ONIGNAL PAGE IS}

OF POOR QUALTY

Table 4 4: Modal Characteristics of $(A+B G)$ as a Function of Output Performance

$\begin{array}{ccccc}\text { Open } & .1015 & .10 & .095 & .19 \\ \text { Lomp } & \text { (deg) }^{2} & \text { (deg) }^{2} & \text { (deg) }^{2} & \text { (no PMAs) }\end{array}$

\begin{tabular}{|c|c|c|c|c|c|c|}
\hline$\omega_{1}(r / s)$ & 1.8 & 3.14 & 3.14 & 3.14 & 3.14 & 3.135 \\
\hline$\zeta_{1}$ & .0015 & 028 & .027 & .0255 & .025 & .01 \\
\hline$\tau_{1}(\mathrm{sec})$ & 111.1 & 11.4 & 11.8 & 125 & 12.74 & 31.9 \\
\hline$\omega_{2}\left(r^{\prime} / s\right)$ & 10.3 & 56. & 62. & 93 & 160. & 63 \\
\hline 52 & $(n) 5$ & .675 & 68 & by 26 & .702 & .08 \\
\hline$\tau(\mathrm{sec})$ & 19.4 & .026 & 024 & .015 & 0,99 & 023 \\
\hline$\omega_{3}(r / s)$ & 31. & $\therefore 9$. & 28.9 & 28.8 & 28.8 & 289 \\
\hline$\zeta_{3}$ & 005 & 0217 & .0185 & .011 & (x)9 & .0116 \\
\hline$\tau_{3}(\sec )$ & 6.45 & 1.6 & 1.37 & 3.16 & 3.95 & 2.16 \\
\hline$\omega_{1}\left(r^{\prime} s\right)$ & 78 & 77.4 & 77. & 77. & 77. & 773 \\
\hline$\zeta 4$ & .0015 & .0965 & .007 & .0072 & M) 52 & .0068 \\
\hline$\tau_{4}(\sec )$ & 2.56 & 2.0 & 1.86 & 1.8 & 2.5 & 2.49 \\
\hline \multicolumn{7}{|c|}{ Sieady-Sizie } \\
\hline \multicolumn{7}{|c|}{ Normalized } \\
\hline CAIG & -- & 4604 & 10.6 & $1 \times 36$ & 591.1 & $65:=$ \\
\hline Varance & & & & & & \\
\hline
\end{tabular}

244 
Aclualor Normelized Verrences

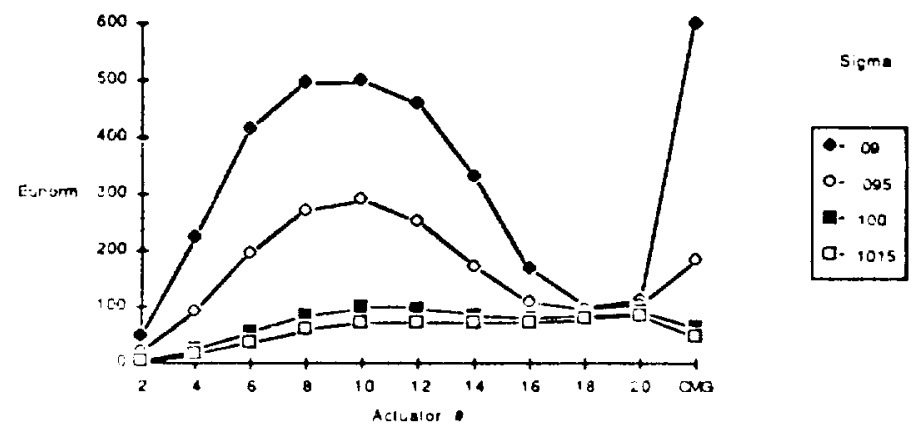


performance data with that obtained from a full set of PMAs and an output variance of $0.1(\operatorname{arcsec})^{2}$ (see Table 4.4).

\subsection{RESULTS FOR DYNAMIC ACTUATORS}

In this section we add actuator dynamics to the SCOLE model and then re-solve the actuator selection problem solved above. The actuator dynamics are given in NASA's original SCOLE document [15] to be first-order with a time constant of 0.1 seconds. That is, for each actuator (both PMA and CMG) the response of the actuator $f_{i}(t)$ to its input signal $u_{i}(t)$ is governed by

$$
\mathrm{f}_{\mathrm{i}}(\mathrm{s}) / \mathrm{u}_{\mathrm{i}}(\mathrm{s})=[1 /(.1 \mathrm{~s}+1)]
$$

or

$$
\dot{\mathrm{f}}_{\mathrm{i}}=-10 \mathrm{f}_{\mathrm{i}}+10 \mathrm{u}_{\mathrm{i}} .
$$

There are several possibilities for the characteristics of the white noise associated with the actuators; white noise may be an input to (and thus be filtered by) the actuator, or it may be additive with the actuator output (thus unfiltered), or both. In this example four different actuator noise models are considered. Recalling that the non-dynamic actuators had additive white noise with intensity $\mathrm{W}$, the following noise cases were studied for dynamic actuators:

1. white actuator input noise of irtensity $\mathrm{W}_{\mathrm{u}}=\mathrm{W}$;

2. white actuator output noise of intensity $\mathrm{W}_{\mathrm{f}}=\mathrm{W}$;

3. both input and output noise, each white and of intensity W; 


\section{4. both input and output noise, each white and of intensity W/2.}

The sensors are assumed non-dynamic (without phase lag).

First we examine the effect of actuator dynamics on the maximal theoretically achievable accuracy. From [3], the lower bound $y_{i}^{*}$ on the steady-state variance of the $i_{t h}$ output is given by

$$
\mathrm{y}_{\mathrm{i}}^{*}=\left[\mathrm{CPC}^{\mathrm{T}}\right]_{\mathrm{ii}} \quad \mathrm{i}=1, \ldots, \text { ny } .
$$

The values of the lower bound on the LOS error for the fourth-order 2-D SCOLE model under study were calculated for the four different actuator noise cases listed above, as well as for the non-dynamic actuator model examined earlier. The results are shown below.

Table 4.5: Maximal Accuracy for Different Actuator Noise Cases

\begin{tabular}{c|c|c|c|c|c} 
Noise Case & No Dynamics & $\mathrm{W}_{\mathrm{u}}=\mathrm{W}$ & $\mathrm{W}_{\mathrm{f}}=\mathrm{W}$ & $\mathrm{W}_{\mathrm{f}}=\mathrm{W}_{\mathrm{u}}=\mathrm{W}$ & $\mathrm{W}_{\mathrm{f}}=\mathrm{W}_{\mathrm{u}}=\mathrm{W} / 2$ \\
\hline $\begin{array}{c}\text { Max. Acc. } \\
(\operatorname{arcsec})^{2}\end{array}$ & .086921 & .0691 & .086921 & .10072 & .07926
\end{tabular}

From Table 4.5 it is clear that the addition of actuator dynamics along with retention of the white noise input to the system states (actuator output noise only, $W_{\mathrm{f}}=\mathrm{W}$ ) does not change the theoretical maximal accuracy; that is, $y^{*}$ is equal for the nondynamic and the $\mathrm{W}_{\mathrm{f}}=\mathrm{W}$ case. Also from the table, filtering of the actuator noise by passing it through finite actuator dynamics clearly improves the maximal accuracy. Finally it is noted that for case (3), $W_{f}=W_{u}=W$, the minimal LOS error is greater than that obtained by all but one of the controllers in the non-dynamic case. Thus for purposes of comparison only cases (1), (2) and (4) are studied in further detail. 
For each of the three actuator noise cases a controller was designed (using OVA) which assigned the steady state LOS error variance to $0.1(\operatorname{arcsec})^{2}$ and minimized the sum of the normalized actuator variances among those actuators whose variances exceed their specifications (normalized variances greater than unity). For each final controller, the dynamic actuator effectiveness values for the PMAs are plotted in Figure 4.12 versus the actuators' position along the $130 \mathrm{ft}$. flexible beam.

For each of the noise cases the most effective actuator location is toward the reflector-end of the beam, with the highest effectiveness values corresponding to actuators located at the beam tip. Recalling the mode shape figures for the open loop flexible modes, the results in Figure 4.12 indicate that the PMAs are used by the optimal controller primarily for control of mode \#1, which accounted for 46.6 percent of the open loop modal cost. It is interesting to compare Figure 4.12 with the plot of effectiveness values for non-dynamic actuators (Figure 4.8); note that the most effective non-dynamic actuators for the controller which achieved LOS error $=0.1(\operatorname{arcsec})^{2}$ were lozated near the center of the beam ( $70 \mathrm{ft}$ from the shuttle). Hence, the optimal beam locations for PMAs in controllers which are achieving the same output performance are affected by the actuator dynamics.

\section{CONCLUSIONS}

The Closed-Loop Input/Output Cost Analysis (CIOCA) method of sensor and actuator selection (SAS) has been extended for application to systems with dynamic sensors and actuators -- that is, systems in which the response of the sensors and actuators to their inputs is not instantaneous but governed by deterministic dynamics. The extended SAS method is applicable to systems in which the deterministic sensor and actuator dynamics are of arbitrary order. Application to simple numerical examples

\section{8}




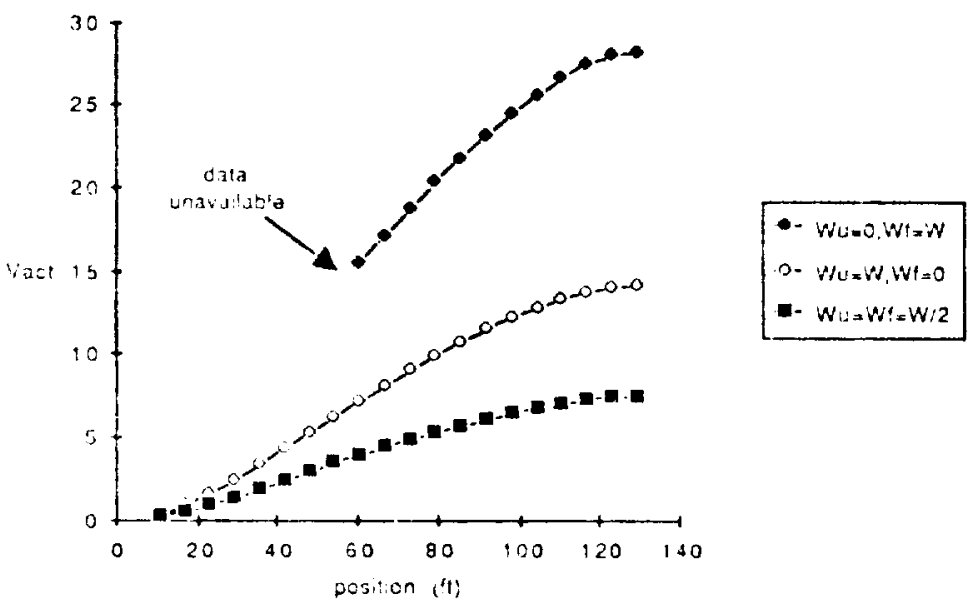

249 
demonstrates the utility of the SAS method. The examples also demonstrated that even uniform sensor dynamics can affect the optimal selection of sensors. Application of the actuator selection method in detail to NASA's SCOLE space structure demonstrated that even uniform actuator dynamics can affect the optimal selection of actuators. 


\section{LIST OF REFERENCES}

[1] Skelton, R.E., and Norris, G.A., "Selection of Noisy Sensors and Actuators in the Presence of Correlated Noise," Journal of Control Theory and Advanced Technology, to appear.

[2] Skelton, R.E., and DeLorenzo, M.L., "Selection of Noisy Actuators and Sensors in Linear Stochastic Systems," Journal of Large Scale Systems, Theory and Applications, Vol. 4, April 1983, pp. 109-136.

[3] Skelton, R.E., and DeLorenzo, M.L., "Space Structure Control Design by Variance Assignment," Journal of Guidance and Control, Vol. 8, July-August 1985, pp. 454-462.

[4] DeLorenzo, M.L., "Selection of Noisy Sensors and Actuators for Regulation of Linear Systems," Ph.D. Thesis, School of Aeronautics and Astronautics, Purdue University, West Lafayette, IN, May 1983.

[5] Skelton, R.E., and Hughes, P.C., "Modal Cost Analysis for Linear MatrixSecond-Order Systems," Journal of Dynamic Systems, Measurement, and Control, Vol. 102, Sept. 1980.

[6] Howell, K.C., and Baxter, M.J., "Some Considerations of Actuator Dynamics in the Attitude Control of a Flexible Beam," (AIAA/AAS Paper 86-2124).

[7] Chiu, JD. and Skelton, R.E., "Optimal Selection of Inputs and Outputs in Linear Stochastic Systems," J. Astronautical Sciences, Vol. XXXI, No. 3, pp. 399-414, July-Sept. 1983.

[8] Goh, C.J., and Caughey, T.K., "On the Stability Problem Caused by Finite Actuator Dynamics in the Collocated Control of Large Space Structures," Int. J. Control, Vol. 41, No. 3, 19:35, pp. 787-802.

[9] Balas, M.J., "Feedback Control of Flexible Systems," IEEE Transactions on Automatic Control, Vol. AC-23, No. 4, 1978, pp. 673-679.

[10] Malandrakis, C.G., "Optimal Sensor and Controller Allocation for a Class of Distributed Parameter Systems," Int. J. Syst. Sci., Vol. 10, No. 5, pp. 463-480, Sept. 1980.

[11] Ichikawa, A. and Ryan, E.P., "Filtering and Control of Distributed Parameter Systems with Point Observations and Inputs," Proc. of the 2nd IFAC Symp. on Control of D.P.S., pp. 347-357, Coventry, Jul. 1977.

[12] Ichikawa, A. and Ryan, E.P., "Sensor and Controller Location Problems for Distributed Parameter Systems," Automatica, Vol. 15, No. 3, pp. 347-352, May 1979.

[13] Hughes, P.C., "Space Structure Vibration Modes: How Many Exist? Which ones are Important?" IEEE Control Systems Magazine, February 1987, pp. 22-28.

[14] Schaechter, D.B., "Control Technology Development," NASA Langley Research Center LSS Tech., Mar 1982, pp. 297-311. 
[15] Taylor, L.W., and Balakrishnan, A.V., "A Mathematical Problem and a Spacecraft Control Laboratory Experiment (SCOLE) Used to Evaluate Control Laws for Flexible Spacecraft ... NASA/IEEE Design Challenge," January 1984, unpublished, available from Lawrence W. Taylor, Jr., Spacecraft Control Branch, NASA Langley Research Center, Hampton, VA, 23665.

[16] Hotz, A.F., Collins, E., and Skelton, R.E., "Linearized Dynamic Model for the NASA/IEEE SCOLE Configuration," NASA Contractor Report 172394, Langley Research Center, Hampton, VA, Sept. 1984.

[17] King, A.M., Norris, G.A., and Skelton, R.E., "Controller Design for Vibration and Shape Control of an Offset Reflector Satellite," contractor report to SPARTA, Inc., May 1986.

[18] Norris, G.A., "Selection of Non-Ideal Noisy Actuators and Sensors in the Control of Linear Systems," Master's Thesis, School of Aeronautics and Astronautics, Purdue University, West Lafayette, IN, May 1987.

[19] McClamrock, H. "Control of Large Space Structures Using Electro-Mechanical Actuaters," CSDL-P-1607, The Charles Starke Draper Lab., Inc., Cambridge, Mass., July 1982. 


\section{Proof of Theorem 1}

Let $\alpha=\left(\mathrm{nx}_{\mathrm{p}}+\mathrm{nx}_{\mathrm{a}}\right)$. The composite system $(2.7 \mathrm{e})$ has a controllability matrix $\mathrm{W}_{\mathrm{c}} \in \mathrm{R}^{\alpha \times\left(\alpha^{*} \mathrm{nu}\right)}$ of the following form

$$
\begin{aligned}
& W_{c}=\left[\begin{array}{l}
W_{c 1} \\
W_{c 2}
\end{array}\right]=\begin{array}{cccc}
0 & B_{0} C_{a} B_{a} & \left(A_{p} B_{o} C_{a} B_{a}+B_{o} C_{a} A_{a} B_{a}\right) \\
B_{a} & A_{a} B_{a} & A_{a}^{2} B_{a}
\end{array} \\
& \cdots \quad\left(A_{p}^{\alpha-2} B_{o} C_{a} B_{a}+A_{p}^{\alpha-3} B_{o} C_{a} A_{a} B_{a}+\cdots+B_{o} C_{a} A_{a}^{\alpha-2} B_{a}\right) \\
& \cdots
\end{aligned}
$$

Now noting that $\mathrm{C}_{\mathrm{a}} \mathrm{A}_{\mathrm{a}}^{\mathrm{i}} \mathrm{B}_{\mathrm{a}}=\mathrm{M}_{\mathrm{i}}$ is the ith Markov parameter for the system of actuator dynamics $(2.7 \mathrm{c}, \mathrm{d}), \mathrm{W}_{\mathrm{cl}}$ may be rewritten

$$
\begin{gathered}
W_{c 1}=\left[0 B_{0} M_{o}\left(A_{p} B_{o} M_{o}+B_{o} M_{1}\right)\left(A_{p}^{2} B_{o} M_{o}+A_{p} B_{o} M_{1}+B_{o} M_{2}\right) \cdots\right. \\
\left.\cdots\left(A_{p}^{\alpha-2} B_{o} M_{o}+A_{p}^{\alpha-3} B_{0} M_{1}+\cdots+B_{0} M_{\alpha-2}\right)\right]
\end{gathered}
$$

The columns of $\mathrm{W}_{\mathrm{c}}$ span the controllable subspace of the composite system. Linear independence of all the rows in $W_{c}$ implies full controllability of the composite system. However, controllability of the original $s_{j}$ stem states, $x_{p}$, requires only that the columns of $W_{c l}$ span the state space for $x_{0}$. This in turn will hold if and only if the matrix $W_{c l}$ has rank $n x_{p}$.

The proof of the Theorem begins with the proof that (A.3) implies (A.4):

$$
\begin{gathered}
\left\{\text { det } M_{k} \neq 0, M_{i}=0, i=0,1, \ldots, k-1\right\} \\
\left.\operatorname{rank} \mid W_{c l}\right\rfloor=n_{x_{p}} \text { (or range space of } W_{c l} \text { has dimension } n_{x_{p}} \text { ) }
\end{gathered}
$$

Note that the last block of $\mathrm{W}_{\mathrm{cl}}$ has the form

$$
W_{c 1(\alpha)}=\left(A_{p}^{\alpha-2} B_{0} M_{o}+A_{p}^{\alpha-3} B_{0} M_{1}+\cdots+B_{0} M_{\alpha-2}\right)
$$

Now let $k \leq \alpha-2$ be the index of the first nonzero Markov parameter, $M_{k}$. (In this case 
the first $k+1$ blocks of $W_{c l}$ are zero.) Next, use is made of two results from linear algebra (" $R[\mathrm{~K}]$ " denotes "range space of $\mathrm{K} ")$,

$$
\begin{gathered}
\{\operatorname{det} \mathrm{K} \neq 0\} \Rightarrow\{R[\mathrm{JK}]=R[\mathrm{~J}]\} \\
R[\mathrm{~J}+\mathrm{K}] \subset R[\mathrm{~J}]+R[\mathrm{~K}]
\end{gathered}
$$

(where " $\subset$ " means "is contained in") to demonstrate the following results which hold when $M_{k}$ is nonsingular

$$
R\left[\mathrm{~B}_{\mathrm{o}}\right]=R\left[\mathrm{~B}_{\mathrm{o}} \mathrm{M}_{\mathrm{k}}\right]
$$

$$
\begin{array}{rl}
R\left[\mathrm{~B}_{\mathrm{o}} \mathrm{A}_{\mathrm{p}} \mathrm{B}_{\mathrm{o}}\right] & =R\left[\mathrm{~B}_{\mathrm{o}}\right]+R\left[\mathrm{~A}_{\mathrm{p}} \mathrm{B}_{\mathrm{o}}\right] \\
& =R\left[\mathrm{~B}_{\mathrm{o}} \mathrm{M}_{\mathrm{k}}\right]+R\left[\mathrm{~A}_{\mathrm{p}} \mathrm{B}_{\mathrm{o}} \mathrm{M}_{\mathrm{k}}\right] \\
& =R\left[\mathrm{~B}_{\mathrm{o}} \mathrm{M}_{\mathrm{k}}\right]+R\left[\mathrm{~A}_{\mathrm{p}} \mathrm{B}_{\mathrm{o}} \mathrm{M}_{\mathrm{k}}+\mathrm{B}_{\mathrm{o}} \mathrm{M}_{\mathrm{k}+1}-\mathrm{B}_{\mathrm{o}} \mathrm{M}_{\mathrm{k}+1}\right] \\
& \subset R\left[\mathrm{~B}_{\mathrm{o}} \mathrm{M}_{\mathrm{k}}\right]+R\left[\mathrm{~A}_{\mathrm{p}} \mathrm{B}_{\mathrm{o}} \mathrm{M}_{\mathrm{k}}+\mathrm{B}_{\mathrm{o}} \mathrm{M}_{\mathrm{k}+1}\right]+R\left[\mathrm{~B}_{\mathrm{o}} \mathrm{M}_{\mathrm{k}+1}\right] \\
& =R\left[\mathrm{~B}_{\mathrm{o}} \mathrm{M}_{\mathrm{k}}\right]+R\left[\mathrm{~A}_{\mathrm{p}} \mathrm{B}_{\mathrm{o}} \mathrm{M}_{\mathrm{k}}+\mathrm{B}_{\mathrm{o}} \mathrm{M}_{\mathrm{k}+1}\right] \\
\therefore R & R\left[\mathrm{~B}_{\mathrm{o}} \mathrm{A}_{\mathrm{p}} \mathrm{B}_{\mathrm{o}}\right] \subset R\left[\mathrm{~B}_{\mathrm{o}} \mathrm{M}_{\mathrm{k}} \mathrm{A}_{\mathrm{p}} \mathrm{B}_{\mathrm{o}} \mathrm{M}_{\mathrm{k}}+\mathrm{B}_{\mathrm{o}} \mathrm{M}_{\mathrm{k}+1}\right]
\end{array}
$$

Eqns (A.8) and (A.9) lead by induction to the main result

$$
\begin{gathered}
R\left[\mathrm{~B}_{\mathrm{o}} \mathrm{A}_{\mathrm{p}} \mathrm{B}_{\mathrm{o}} \cdots \mathrm{A}_{\mathrm{o}}^{\alpha-\mathrm{k}-2} \mathrm{~B}_{\mathrm{o}}\right] \subset R\left[\mathrm{~B}_{\mathrm{o}} \mathrm{M}_{\mathrm{k}} \mathrm{A}_{\mathrm{p}} \mathrm{B}_{\mathrm{o}} \mathrm{M}_{\mathrm{k}}+\mathrm{B}_{\mathrm{o}} \mathrm{M}_{\mathrm{k}+1} \cdots\right. \\
\left.\mathrm{A}_{\mathrm{p}}^{\alpha-\mathrm{k}-2} \mathrm{~B}_{\mathrm{o}} \mathrm{M}_{\mathrm{k}}+\cdots \mathrm{B}_{\mathrm{o}} \mathrm{M}_{\alpha-2}\right]
\end{gathered}
$$

that is,

$$
R\left[\mathrm{~B}_{\mathrm{o}} \mathrm{A}_{\mathrm{p}} \mathrm{B}_{\mathrm{o}} \cdots \mathrm{A}_{\mathrm{p}}^{\alpha-\mathrm{k}-2} \mathrm{~B}_{\mathrm{o}}\right] \subset R\left[\mathrm{~W}_{\mathrm{cl}}\right]
$$


Condition (A.3) leads to (A.10). Thus, given (A.3) together with $\left(A_{p}, B_{0}\right)$ controllable, the columns of $\mathrm{W}_{\mathrm{cl}}$ are guaranteed to span the $\mathrm{nx}_{\mathrm{p}}$-dimensional state space for $\mathrm{x}_{\mathrm{p}}$ as long as

$$
\alpha-k-2 \geq \mathrm{nx}_{\mathrm{o}}-1
$$

that is, as long as

$$
\mathrm{k} \leq \mathrm{nx}_{\mathrm{a}}-1
$$

In fact, the index $\mathrm{k}$ of the first nonzero Markov parameter for the system (2.7) will always satisfy (A.11). To show this, simply note that by observability of $\left(A_{a}, B_{a}\right)$, the observability matrix $\mathrm{W}_{\mathrm{oa}}$ for (2.7) has full column rank:

$$
\operatorname{rank}\left(\mathrm{W}_{\mathrm{oa}}\right)=\mathrm{nx}_{\mathrm{a}}
$$

From (A.12),

$$
\left\{\mathrm{W}_{\mathrm{oa}} \mathrm{B}_{\mathrm{a}}=0\right\} \Rightarrow\left\{\mathrm{B}_{\mathbf{a}}=0\right\} \Rightarrow\left\{\text { Contradiction of }\left(\mathrm{A}_{\mathrm{a}}, \mathrm{B}_{\mathrm{a}}\right) \text { controllable }\right\}
$$

Thus,

$$
W_{o d} B_{a}=\left[M_{o}^{T}, M_{1}^{T}, \ldots, M_{n y-1}^{T}\right]^{T} \neq 0
$$

and so the validity of (A.11) is guaranteed for (2.7) completing the proof that

$$
\begin{gathered}
\left\{\left[\left(A_{p}, B_{0}\right) \text { controllable }\right] \&\left[M_{k} \neq 0, M_{i}=0, i=0,1, \ldots, k-1\right]\right\} \\
\Rightarrow\left\{x_{p} \text { controllable } u\right\}
\end{gathered}
$$

The usefulness of (A.15) stems from the fact that by meeting certain mildly restrictive conditions the actuator dynamics can be guaranteed not to destroy controllability of the original system states $\mathbf{x}_{\mathrm{p}}$, regardless of the pole/zero location for the plant.

\section{5}


It remains to prove the equivalence of the condition (A.3) and the requirements on the individual actuators' numbers of poles and zeros. First, note that since each actuator is a single input, single output (SISO) system, then the Markov parameters $\mathrm{M}_{i}$ for the lumped actuator dynamics (2.7) are diagonal matrices of the following form:

$$
\mathrm{M}_{\mathrm{i}}=\operatorname{diag}\left[\mathrm{m}_{1 \mathrm{i}}, \mathrm{m}_{2 \mathrm{i}}, \mathrm{m}_{3 \mathrm{i}}, \ldots, \mathrm{m}_{\mathrm{nui}}\right]
$$

where $m_{j i}$ is the (scalar) $i_{t h}$ Markov parameter for the $j_{t h}$ actuator. Thus the condition (A.3) is met if and only if the index $i$ of the first nonzero markov parameter is equal among all the actuators.

The input/output transfer function for any $\mathrm{n}_{\mathrm{th}}$ order SISO system has the form:

$$
T(s)=\left(c_{n-1} s^{n-1}+c_{n-2} s^{n-2}+\cdots+c_{0}\right) /\left(s^{n}+d_{n-1} s^{n-1}+\cdots+d_{o}\right)
$$

The scalar Markov parameters $m_{i}$ for the SISO system with transfer function (A.20) may be shown to be given by:

$$
\begin{gathered}
m_{0}=c_{n-1} \\
m_{1}=c_{n-2}-d_{n-1} n_{0} \\
n_{2}=c_{n-3}-d_{n-2} \\
\vdots \\
n_{n}=c_{o}-d_{n-1} n_{1} \\
\vdots
\end{gathered}
$$

From (A.18), $n_{i}$ is the first nonzero Markov parameter for a system when the number of zeros in its transfer function is

$$
z=n-i-1
$$

Letting $n_{j}$ and $z_{j}$ equal the number of poles and zeros for the $j_{t h}$ actuator, respectively, (A.19) yields the conclusion that

$$
256
$$




$$
\left\{\operatorname{det} M_{k} \neq 0, M_{i}=0, i=0,1, \ldots, k-1\right\} \Leftrightarrow\left\{\left(n_{j}-z_{j}\right)=\left(n_{i}-z_{i}\right) \bigvee i, j, \in(1,2, \ldots, n u)\right\}(A .20)
$$

Thus it is concluded that

$$
\left\{\left(n_{j}-z_{j}\right)=\left(n_{i}-z_{i}\right) \bigvee i, j, \in(1,2, \ldots, n u)\right\} \Rightarrow\left\{x_{p} \text { is controllable } u\right\}
$$


258 